\title{
Analisis dan Desain Tata Kelola Teknologi Informasi Menggunakan Framework COBIT 2019 pada PT. XYZ
}

\author{
Diki Darmawan1, Agustinus Fritz Wijaya² \\ 1,2 Program Studi Sistem Informasi, Fakultas Teknologi Informasi, \\ Universitas Kristen Satya Wacana \\ Salatiga, Jawa Tengah, Indonesia \\ Email: 1682018227@student.uksw.edu, 2 agustinus.wijaya@uksw.edu
}

\begin{abstract}
Tata kelola teknologi Informasi merupakan langkah mitigasi penyelarasan implementasi teknologi informasi dengan tujuan perusahaan. Tata kelola teknologi informasi yang tepat akan membantu organisasi untuk mampu bersaing dengan kompetitor-kompetitor lain, maka dari itu penerapan tata kelola teknologi menggunakan kerangka kerja COBIT 2019 akan sangat memiliki pengaruh dalam menunjang tujuan perusahaan. Pada kemajuan era industri saat ini banyak sekali kemajuan dan memberikan pengaruh yang bersar terhadap berbagai aspek kehidupan, salah satunya bidang bisnis yaitu munculnya online shop. Sehingga di temukan permasalahan di perusahaan PT. XYZ adalah belum pernah ada tindakan penilaian tata kelola teknologi informasi secara menyeluruh, selain itu juga ditemukan kendala dalam pengelolaan data pesanan dan data stock barang pada perusahaan. Analisa yang dilakukan dengan acuan Governance System Design Workflow yang tertera pada COBIT 2019.
\end{abstract}

Keywords: COBIT 2019, Online Shop, Governance System Design Workflow.

\section{PENDAHULUAN}

Melihat perkembangan teknologi informasi yang selaras dengan perkembangan zaman begitu pesat menyebabkan peran efisiensi dan efektivitas menjadi peran strategis bagi produktifitas perusahaan. Tata kelola teknologi informasi yang tidak terencana secara sistematis akan mengakibatkan perusahaan tidak memiliki skala prioritas sehingga penerapan teknologi informasi tidak selaras dengan tujuan perusahaan [1].

Hal ini tentunya akan berdampak pada penurunan produktifitas perusahaan, ditambah lagi semakin banyak perusahaan sejenis yang berdiri, maka perusahaan harus mampu memenangkan persaingan dan 
Journal of Computer and Information Systems Ampera

Vol. 3, No. 1, January 2022 e-ISSN: 2775-2496

https://journal-computing.org/index.php/journal-cisa/index

mempertahankan. Oleh karena itu diperlukannya tata kelola teknologi informasi untuk mendukung strategi bisnis perusahaan agar mampu mencapai tujuan bisnisnya dengan pemanfaatan teknologi informasi dengan tepat [2].

Kemampuan tersebut terkait langsung dengan bagaimana perusahaan memilih strategi, aplikasi dan kebijakan organisasi yang tepat dengan berfokus pada sistem informasi/teknologi informasi, maka dari itu perlu diterapkan tata kelola teknologi yang sesuai dengan tujuan perusahaan(SI/TI) [3]. Tata kelola teknologi yang tepat akan membantu organisasi untuk mampu bersaing dengan kompetitor-kompetitor lain, maka dari itu penerapan tata kelola teknologi menggunakan kerangka kerja COBIT 2019 akan sangat memiliki pengaruh dalam menunjang tujuan perusahaan [4].

Perusahaan saat ini lebih banyak menggunakan aplikasi berbasis web dan/atau mobile yang jangkauan penggunanya lebih luas. Server yang digunakan adalah server berbasis cloud misalkan google drive yang disediakan oleh pihak ketiga sebagai media host untuk SI yang telah diterapkan. Selain menerapkan SI dengan pengembangan sendiri, beberapa perusahaan juga telah memanfaatkan e-commerce pihak ketiga untuk menghemat biaya pengembangan sistem. Penggunaan website dan media ;sehingga kegiatan promosi dan pemasaran dapat berjalan efektif dan dapat menjangkau lebih banyak calon customer [5].

Dikarenakan belum pernah adanya penerapan sistem tata kelola menggunakan framework Cobit 2019 atau penelitian serupa di perusahaan PT.XYZ, penelitian ini mengacu pada penelitian "Perancangan Tata Kelola Teknologi Informasi Menggunakan Framework Cobit 2019 Pada Hotel Xyz" oleh Anastasia, Priscilla Novita Atrinawati, Lovinta Happy (2020). Tata Kelola TI diterapkan di perusahaan untuk kemudian mengelola layanan TI agar lebih baik, penerapan panduan rancangan tata kelola TI yang dinilai dapat membantu mengoptimalkan investasi TI-enable, serta memastikan pengiriman dan menyediakan ukuran yang jelas apabila terjadi kesalahan adalah COBIT (Control Objective for Information and Realated Technology). Berdasarkan penelitian yang telah menerapkan framework COBIT 2019 ini terbukti dapat mengidentifikasi permasalahan dan menghasilkan beberapa rancangan tata kelola/ manajemen TI, sehingga dapat didapat proses penting yang memiliki tingkat kapabilitas tinggi [6]. 
https://journal-computing.org/index.php/journal-cisa/index

Tata kelola merupakan kumpulan dari berbagai metode dan aturan dalam menjalankan sebuah prosedur untuk mencapai tujuan strategis yang disepakati. Selain itu, tata kelola dapat dilakukan dengan tujuan mengatasi masalah yang dimiliki oleh sebuah perusahaan atau organisasi. Struktur sistem tata kelola TI terdiri atas komponen-komponenyang membangun sistem tata kelola TI, yaitu: aktiva manusia, kendali dan regulasi. Dalam konteks ini,manusia termasuk ke dalam sistem tata kelola $\mathrm{TI}$, karena manusia merupakan komponen yang memiliki peran dan fungsi yang penting dalam merancang, membuat keputusan, melaksanakan dan mengevaluasi sistem tata kelola TI. Pada era industri 4.0 tentu saja sudah melewati dan mengalami banyak perkembangan yang terjadi salah satunya ialah kinerja tata kelola yang juga mengalami perkembangan. Salah satu kunci dari revolusi industri 4.0 adalah kecepatan perubahan yang dialami organisasi dan individu, karena inovasi teknologi yang muncul menciptakan cara untuk mengembangkan, bertukar dan mendistribusikan nilai di seluruh masyarakat.

Kemajuan Teknologi Informasi (TI) perlu dimanfaatkan para pelaku Usaha Kecil dan Menengah (UKM) untuk mengembangkan bisnisnya melalui e-Commerce, peluangnya terbuka lebar dan secara teknis mudah dijalankan. Pemanfaatan teknologi informasi untuk perdagangan dan jasa atau yang dikenal dengan eCommerce bisa dilakukan baik untuk $\mathrm{B} 2 \mathrm{~B}$ (business to business) misalnya antara pabrik dengan pemasok bahanbaku atau antara distributor dengan dealer; maupun untuk B2C (businessto consumer) seperti perusahaan transportasi dengan calon penumpang,antara rumah sakit dengan pasien dan antara pedagang dengan pembeli. Selain itu ada jenis pemanfaatan untuk e-Marketplace, pasar yang terbentuk secara maya mempertemukan penjual dan pembeli.

Seiring dengan perkembangan TI saatini, pemanfaatan TI telahmenjadi kebutuhan yang mendasar dalammenopang pelaksanaan bisnis organisasi yang efektif, efisien dan transparan, maka pengelolaan TI yang baik menjadi suatu kebutuhanyang penting untuk dilakukan oleh sebuah organisasi. Dengan ilmu pengetahuan serta teknologi yang terus berkembang seiring berjalannya waktu, perusahaan dituntut dalam menemukan berbagai terobosan strategi yang mampu bersinergi dalam pemanfaatan TI untuk mencapai tujuan perusahaan. Apabiladalam suatu perusahaan terdapat tata kelola TI yang berjalan tidak efektif, maka akan membawa dampak negatif bagi perusahaan. 
Journal of Computer and Information Systems Ampera

Vol. 3, No. 1, January 2022 e-ISSN: 2775-2496

https://journal-computing.org/index.php/journal-cisa/index

Control Objective for Information and Related Technology atau yang disingkat dengan COBIT, merupakan framework yang rilis oleh IT Governance Institute (ITGI) dapat digunakan secara internasional. COBIT dapat digunakan perusahaan dalam mengontrol penerapan TI dalam perusahaan. Adapun definisi online shop, adalah suatu proses pembelian barang atau jasa dari mereka yang menjual barang atau jasa melalui internet dimana antara penjual dan pembeli tidak pernah bertemu atau melakukan kontak secara fisik yang dimana barang yang diperjualbelikan ditawarkan melalui display dengan gambar yang ada di suatu website atau toko maya. Setelahnya pembeli dapat memilih barang yang diinginkan untuk kemudian melakukan pembayaran kepada penjual melalui rekening bank yang bersangkutan. Setelah proses pembayaran di terima, kewajiban penjual adalah mengirim barang pesanan pembeli ke alamat tujuan.

Tata kelola TI menjadi tanggung jawab dan bentuk praktik kerja yang biasanya digunakan para eksekutif bisnis untuk dapat memiliki pandangan pada sasaran perusahaan. Tata kelola TI bisa digunakan oleh organisasi pada level eksekutif untuk mengendalikan risiko yang bisa terjadi dan memastikan segala bentuk sumber daya perusahaan agar dapat digunakan dengan sesuai. Pada akhirnya tata kelola perusahaan yang lakukan secara baik bisa mempengaruhi tingkat kepercayaan serta perlindungan investasi di masa depan yang lebih terjamin [3].

Kemajuan era industri saat ini banyak sekali kemajuan dan memberikan pengaruh yang bersar terhadap berbagai aspek kehidupan, salah satunya bidang bisnis yaitu munculnya online shop. Konsumen yang ingin membeli suatu barang biasanya mendatangi toko untuk melihat kondisi fisik dari barang yang akan dibeli. Online Shop atau Online shopping merupakan proses dimana terjadinya transaksi meliputi pembelian barang dan lainlain dari penjual melalui media daring atau internet. Online Shop proses transaksi tanpa bertemu bisa dilakukan di mana saja dan kapan saja dengan syarat terhubung dalam sistem perdagangan dan jaringan internet [7].

Tata Kelola TI juga menjadi tanggung jawab dan bentuk praktik kerja yang biasanya digunakan para eksekutif bisnis untuk dapat memiliki pandangan pada sasaran perusahaan. Tata Kelola TI digunakan organisasi untuk mengendalikan risiko yang bisa terjadi dan memastikan segala bentuk sumber daya perusahaan agar dapat digunakan dengan sesuai. Pada akhirnya tata kelola perusahaan yang dilakukan secara baik dapat 


\section{Journal of Computer and Information Systems Ampera}

Vol. 3, No. 1, January 2022 e-ISSN: 2775-2496

https://journal-computing.org/index.php/journal-cisa/index

mempengaruhi tingkat kepercayaan serta perlindungan investasi di masa depan yang lebih terjamin.

\section{METODE PENELITIAN}

Dalam penelitian ini, terdapat beberapa tahapan penelitian yang dilakukan, tahapan yang dilakukan digambarkan menurut diagram alir pada gambar 1 di bawah ini.

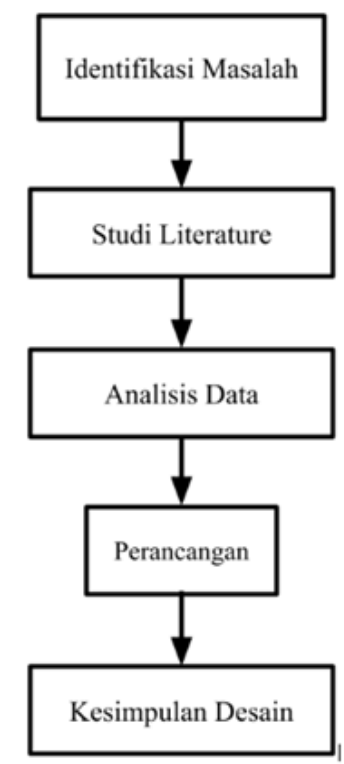

Gambar 1. Diagram Alir Penelitian

Pada tahapan identifikasi Masalah dilakukan proses wawancara sebagaimana metode pengumpulan data pada perusahaan terkait profil perusahaan, tujuan perusahaan, dan terkait sejauh mana implementasi teknologi informasi diterapkan pada perusahaan. Sehingga ditemukan permasalahan di perusahaan PT.XYZ adalah belum pernah ada tindakan penilaian tata kelola teknologi informasi secara menyeluruh, selain itu juga ditemukan kendala dalam pengelolaan data pesanan dan data stock barang pada perusahaan. Maka dari itu , dirasa perlu di adakan proses tata kelola teknologi informasi agar pemanfaatan teknologi informasi tepat sasaran dan lebih terstruktur sehingga tujuan perusahaan tercapai dengan semestinya. 
Vol. 3, No. 1, January 2022 e-ISSN: 2775-2496

https://journal-computing.org/index.php/journal-cisa/index

Teknik ini dilakukan dengan tujuan untuk mengungkapkan berbagai teoriteori yang relevan dengan permasalahan yang sedang dihadapi/diteliti sebagai bahan rujukan dalam pembahasan hasil penelitian. Pengertian Lain tentang Studi Literatur adalah mencari referensi teori yang relefan dengan kasus atau permasalahan yang ditemukan. Tahap studi literatur di terapkan demi mendukung serta menguatkan data yang telah di dapat dalam hal penelitian. Studi literatur di lakukan dengan cara mengumpulkan artikel ilmiah dan berbagai sumber referensi artikel penelitian terkait tata kelola teknologi informasi sebagai tolak ukur penelitian.

Pada tahap analisis, analisa di lakukan dengan acuan Governance System Design Workflow yang tertera pada COBIT 2019. Dengan melakukan pemeriksaan di berbagai bagian antara lain adalah pemeriksaaan konteks, strategi dan lingkungan bisnis ( hal ini untuk mencapai pemahaman yang jelas terhadap strategi perusahaan), serta menentukan penyelarasan yang hendak di sasar dan hasil dari penyelarasan tata kelola teknologi informasi, untuk menimbang sejauh mana penerapan dan kebutuhan teknologi hingga penerapan tata kelola TI.

Pada langkah ini, kegiatan perancangan sistem tata kelola terdiri dari: Menelusuri setiap Design Factors (DF) dari Enterprise Strategy DF1 hingga enterprise size DF11. Pada proses perancangan sistem tata kelola terdapat faktor desain yang dipertimbangkan, diantaranya ialah:

\section{A. Design Factor 1 - Enterprise Strategy}

Perusahaan memiliki strategi yang beragam sesuai dengan bidang bisnisnya. Dalam design factor ini terdapat beberapa jenis strategi perusahaan seperti fokus pada pertumbuhan perusahaannya, fokus pada produk dan layanan yang inovatif kepada klien, fokus pada minimalisasi biaya dalam jangka pendek, serta fokus pada penyediaan layanan yang stabil dan berorientasi kepada klien.

\section{B. Design Factor 2 - Enterprise Goals}

Setiap perusahaan harus memprioritaskan sasaran perusahannya sesuai dengan strategi perusahaan yang dipilih. Untuk menerjemahkan tujuan perushaan ke dalam peringkat relatif pentingnya tata kelola dan tujuan manajemen, stakeholder harus membuat pilihan yang jelas ketika memilih tujuan perusahaan. 
https://journal-computing.org/index.php/journal-cisa/index

\section{Design Factor 3 - IT Risk Profile}

Memahami profil risiko perusahaan yaitu memahami skenario risiko mana yang dapat memengaruhi perusahaan, dan bagaimana menilai dampaknya dan kemungkinan terwujudnya. Untuk itu perlu dilakukannya analisis risiko tingkat tinggi pada perusahaan, seperti melakukan identifikasi risiko yang relevan.

D. Design Factor 4 - I\&T Related Issues.

Masalah TI dapat diidentifikasikan atau dilaporkan melalui risiko manajemen, audit, manajemen senior atau pemangku kepentingan eksternal. Perbedaan yang jelas harus dibuat dalam masalah peringkat I\&T, untuk memberikan input yang diperlukan untuk menentukan prioritas desain tata kelola.

\section{E. Design Factor 5 - Threat Landscape}

Tipikal ancaman yang dihadapi oleh perusahaan juga menjadi salah satu faktor desain sistem tata kelola yang tepat. Terdapat 2 macam ancaman yaitu ancaman normal dan ancaman tinggi.

\section{F. Design Factor 6 - Compliance Requirement}

Kebutuhan dan tuntutan kepatuhan yang harus dipenuhi oleh perusahaan merupakan salah satu faktor yang penting.

Pada tahap ini terdapat 3 jenis kebutuhan/tuntutan kepatuhan yaitu rendah, normal, dan tinggi.

\section{G. Design Factor-Role Of IT}

Peran TI dalam perusahaan juga menjaadi faktor yang penting. Dimana menilai apakah TI diposisikan sebagai strategic, support, maupun pabrik.

\section{H. Design Factor - Sourcing Model of IT}

Model pengalihan daya TI yang diterapkan dalam perusahaan biasanyamenggunakan layanan TI dengan beberapa model seperti outsourcing, cloud, insourced, atau hybrid.

I. Design Factor 9 - IT Implementation Methods

Terdapat beberapa tipe metode implementasi TI seperti Agile, DevOps,Traditional, dan Hybird.

\section{J. Design Factor 10 - Technology Adoption Strategy}




\section{Journal of Computer and Information Systems Ampera}

Vol. 3, No. 1, January 2022 e-ISSN: 2775-2496

https://journal-computing.org/index.php/journal-cisa/index

Strategi mengadopsi teknologi baru dalam perusahaan terdapat beberapa jenis sifatnya. Seperti first mover dimana perusahaan tersebut selalu ingin mengadopsi teknologi baru sesegera mungkin. Kemudia terdapat follower dimana perusahaan menunggu yang lain menerapkan teknologi tersebut baru dia ikuti, dan slow adopter dimana perusahaan sangat lambat dalam pengadopsian teknologi baru.

- Menentukan masing-masing design factors yang berlaku dan tidak.

- Menentukan nilai potensial untuk design factors yang berlaku untuk perusahaan.

- Hasil dari setiap pertimbangan design factors adalah daftar peringkat tujuan tata kelola dan manajemen.

\section{K. Design Factor 11- All Design Factor}

Setelah di lakukan proses sistem tata kelola menggunakan framework Cobit 2019 di perusahaan PT.XYZ ini kiranya dapat menghasilkan sebuah sistem desain tata kelola yang tepat bagi perusahaan, sehingga perusahaan akan lebih tepat dalam pengambilan keputusan terkait implementasi IT Goverment demi keselarasan Teknologi Informasi dan tujuan bisnis perusahaan.

\section{HASIL DAN PEMBAHASAN}

\subsection{Desain Factor 1: (Enterprise Strategy)}

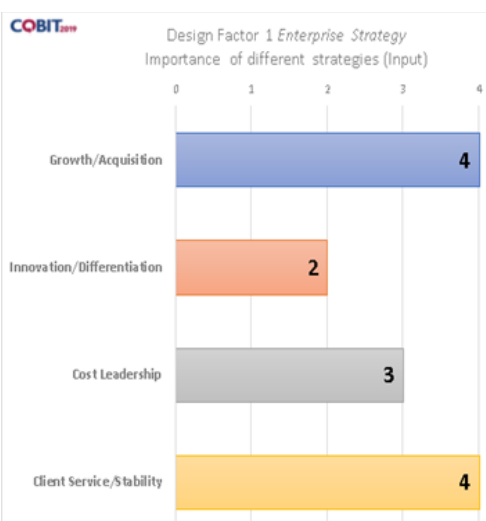

Gambar 2. Design Factor 1 (Enterprise Strategy). 


\section{Journal of Computer and Information Systems Ampera}

Vol. 3, No. 1, January 2022 e-ISSN: 2775-2496

https://journal-computing.org/index.php/journal-cisa/index

Enterprise Strategy pada study kasus di perusahaan PT.XYZ dapat dilihat pada Gambar 2. Pada hasil analisa berdasarkan hasil wawancara dengan stakeholder yakni owner PT.XYZ, Strategi utama dari perusahaan adalah terkait dengan pertumbuhan perusahaan yang dapat diraih salah satunya dengan cara mengoptimalkan daya tarik pada pasar, maka dari itu terjadi keselarasan nilai tertinggi pada aspek Growth/Acquisition dan pada Client Service/Stability dengan nilai 4, kemudian di ikuti dengan nilai 3 pada Cost Leadership sebab faktor biaya juga menjadi acuan strategi utama terkait dengan pertumbuhan perusahaan, adapun nilai terendah yakni 2 di peruntukan pada aspek Innovation/Differentiation sebab melihat dari profil dan strategi perusahaan tidaklah berfokus pada hal baru dan hanya berfokus pada pemasaran produk.

\subsection{Desain Factor 2: (Enterprise Goals)}

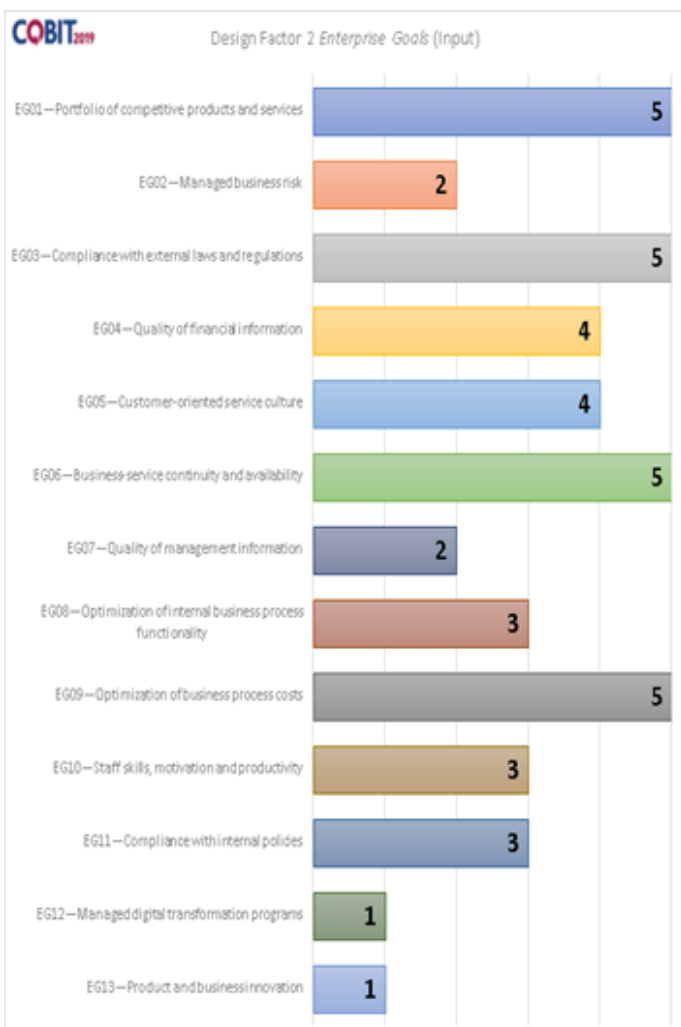

Gambar 3. Desain Factor 2 (Enterprise Goals). 


\section{Journal of Computer and Information Systems Ampera}

Vol. 3, No. 1, January 2022 e-ISSN: 2775-2496

https://journal-computing.org/index.php/journal-cisa/index

Enterprise Goals pada study kasus di perusahaan PT.XYZ dapat dilihat pada

Gambar 3. Pada Enterprise Goals dijelaskan bahwa EG1, EG3, EG6, EG9 dengan nilai tertinggi kemudian dari berbagai hasil data tersebut diselaraskan dengan tujuan perusahaan, maka dapat disimpulkan bahwa alignment goals bertumpu pada tujuan perusahaan sesuai bidang dan kebutuhan dalam meraih keberhasilan dalam strategi perusahaan. Kemudian berdasarkan alignment goals dilanjutkan dengan mapping pada "Resulting Governance / Management Objective Importance" menurut Framework Cobit 2019 menghasilkan domain dengan Relative Importance tertinggi yaitu APO04, BAI08, AP002, AP007, AP008.

\subsection{Desain Factor 3: (Risk Profile)}

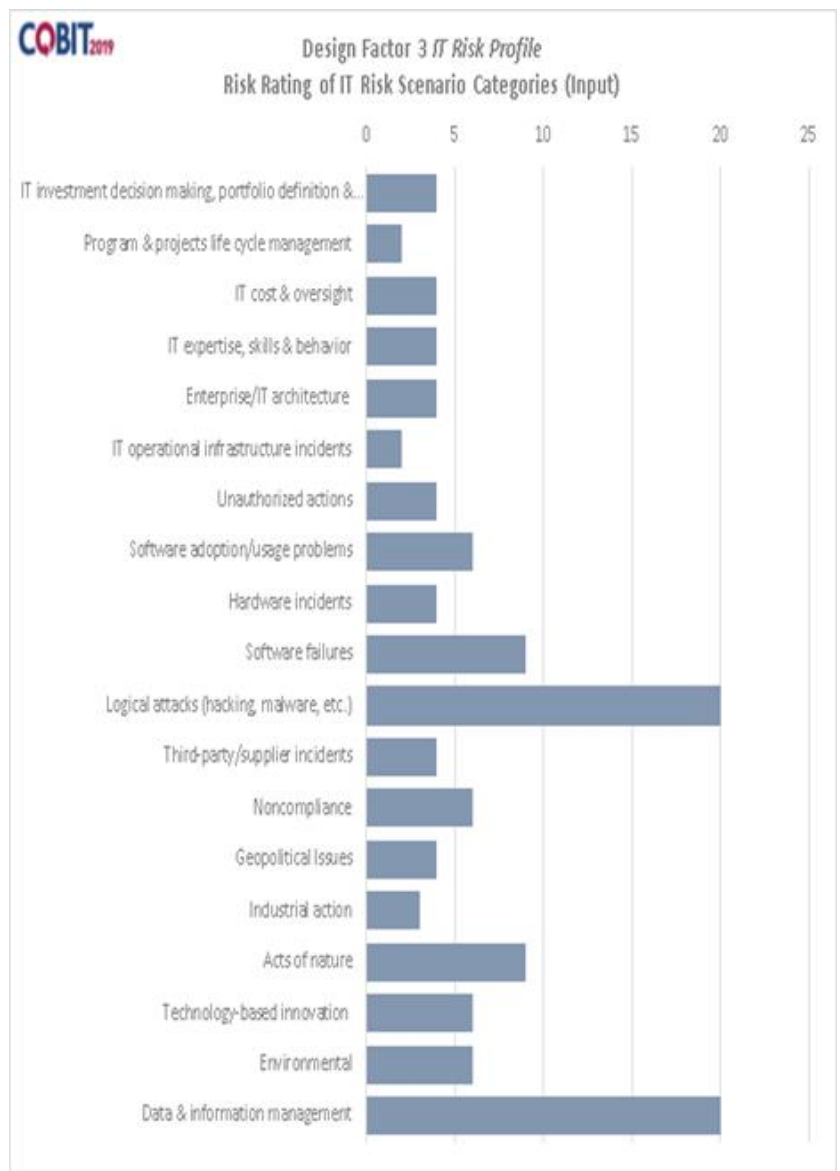

Gambar 4. Desain Factor 3 (Risk Profile). 


\section{Journal of Computer and Information Systems Ampera}

Vol. 3, No. 1, January 2022 e-ISSN: 2775-2496

https://journal-computing.org/index.php/journal-cisa/index

Risk Profile pada study kasus di perusahaan PT.XYZ dapat dilihat pada Gambar 4. Pada hasil data wawancara menunjukkan bahwa nilai Logical attacks sangat tinggi, sebab perusahaan secara total bertumpu pada sistem SI/TI hampir dalam seluruh operasional management penjualannya maka akan sangat merugikan jika terjadi serangan logis. Kemudian dilakukan mapping berdasarkan data Risk profile tertinggi ke dalam domain Cobit 2019, menghasilkan AP012, AP013, BAI06, dan AP014 sebagai domain yang memiliki Relative Importance dengan nilai tertinggi.

\subsection{Desain Factor 4: (I\&T Realated Issues)}

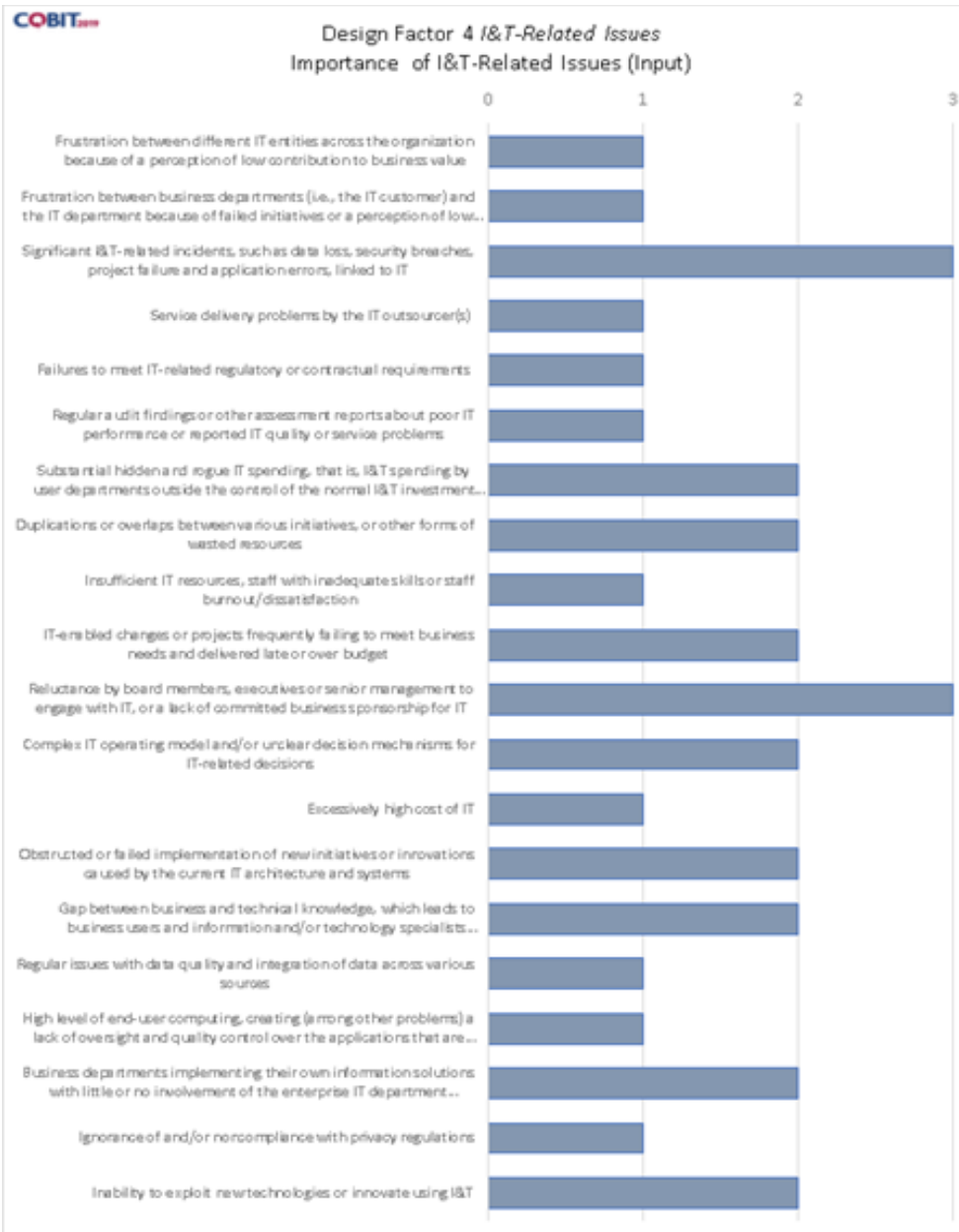

Gambar 5. Desain Factor 4 (I\&T Realated Issues). 


\section{Journal of Computer and Information Systems Ampera}

Vol. 3, No. 1, January 2022 e-ISSN: 2775-2496

https://journal-computing.org/index.php/journal-cisa/index

I\&T Related Issues pada perusahaan dapat berdasarkan hasil wawancara bahwa Significant I\&T-realated incidents memiliki tingkat keseriusan sebab kinerja perusahaan bertumpu pada IT maka dari itu pantas di berikan nilai 3 pada I\&T Related Issues.

Selain itu kategori Reluctance by board members, executives or senior management to engage with IT, or a lack of committed business sponsorship for IT memiliki tingkat keseriuasan bernilai 3 sebab kinerja perusahaan mengutamakan komponen TI secara kompleks sebagaimana PT.XYZ merupakan perusahaan online maka akan sangat diperhatikan bagian proses pengadaan aset dan inventaris TI dalam perusahaan secara kompleks demi pertumbuhan perusahaan. Maka berdasarkan hasil I\&T Related Issues dengan nilai tertinggi berdasarkan analisa ini, dilakukan mapping pada framework Cobit 2019 dan menghasilkan domain sebagaimana BAI01, BAI11, AP002, AP004, dan DSS04.

\subsection{Desain Factor 5: (IT Threat Landscape)}

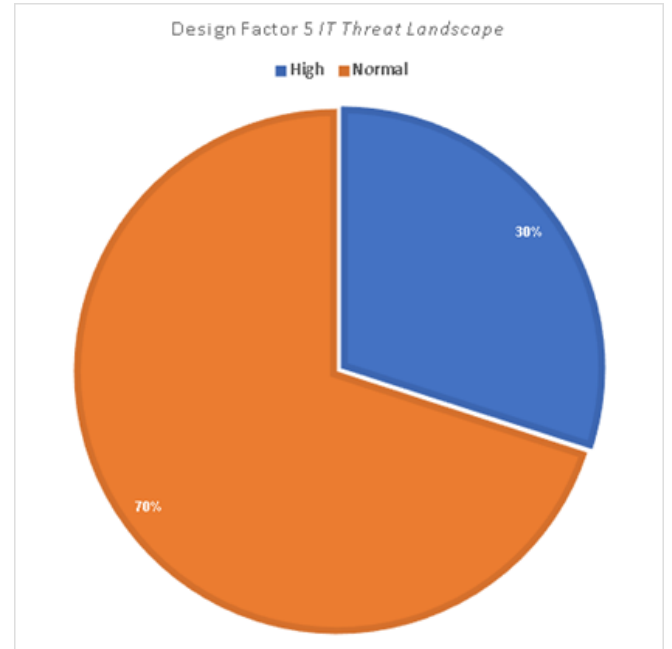

Gambar 6. Design Factor 5 (IT Threat Landscape).

Threat Landscape pada perusahaan PT.XYZ di jelaskan pada Gambar 6. Ancaman normal dinilai 70\% sebab mengingat perusahaan yang berbasis online sangat rentan terhadap ancaman operasional terkait dengan koneksi internet dan perangkat yang digunakan dalam operasional perusahaan. 


\section{Journal of Computer and Information Systems Ampera}

Vol. 3, No. 1, January 2022 e-ISSN: 2775-2496

https://journal-computing.org/index.php/journal-cisa/index

\subsection{Desain Factor 6: (Compliance Requirements)}

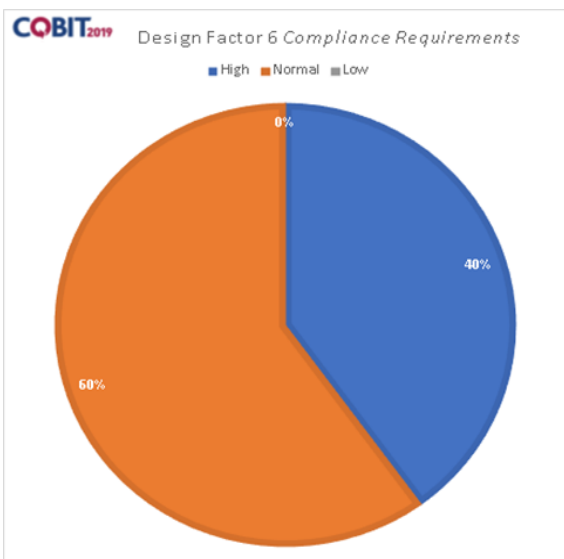

Gambar 7. Desain Factor 6 (Compliance Requirements)

Compliance Requirement pada perusahaan PT.XYZ pada Gambar 7. Menjelaskan bahwa perusahaan menerapkan standar operasional perusahaan yang kompleks dan normal, karenaPT.XYZmenerapkan peraturan yang tidak membebani karyawan selain itu perusahaan juga mematuhi peraturan-peraturan sistem penjualan yang ada pada platform/marketplace yang di gunakan sebagai media penjualan.

\subsection{Desain Factor 7: (Role Of IT).}

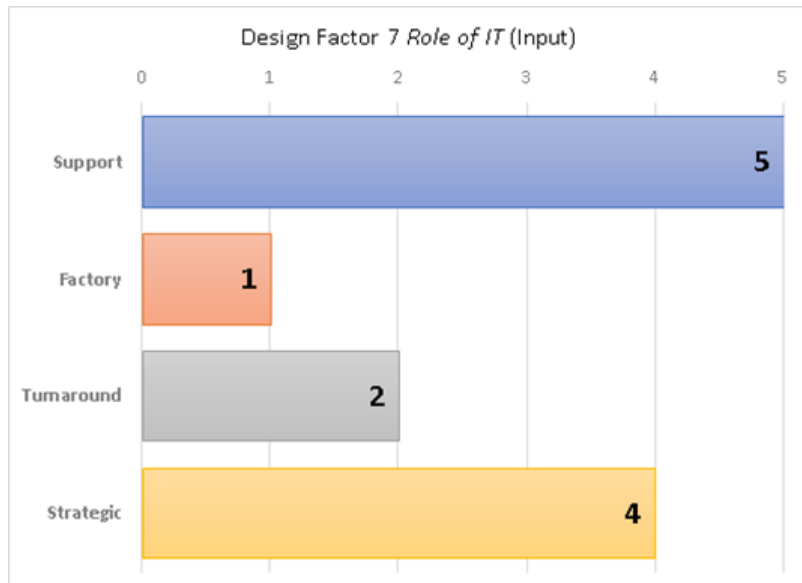

Gambar 8. Desain Factor 7 (Rple Of IT). 


\section{Journal of Computer and Information Systems Ampera}

Vol. 3, No. 1, January 2022 e-ISSN: 2775-2496

https://journal-computing.org/index.php/journal-cisa/index

Role of IT pada studi kasus PT.XYZ dijelaskan pada Gambar 8. Berdasarkan hasil wawancara maka dapat dijelaskan bahwa Support teknologi sangat utama dalam operasional perusahaan maka dari itu disini diberikan nilai 4, nilai 1 pada Factory di sebabkan bahwansanya perusahaan tidak hanya terpaku pada satu teknologi saja jadi apabila memungkinkan ada kendala pada salah satu sistem yang digunakan tidak mempengaruhi kinerja perusahaan secara kompleks, sarana dan peranan TI di perusahaan menunjang operasional perusahaan sebagai pengembangan bisnis maka dari itu Turnaround diberikan nilai 2, Strategic dengan nilai 4 sebab penerapan TI di perusahaan PT.XYZ cukup kompleks dan mencakup segala aspek proses bisnis perusahaan.

\subsection{Desain Factor 8: (IT Sourching Model)}

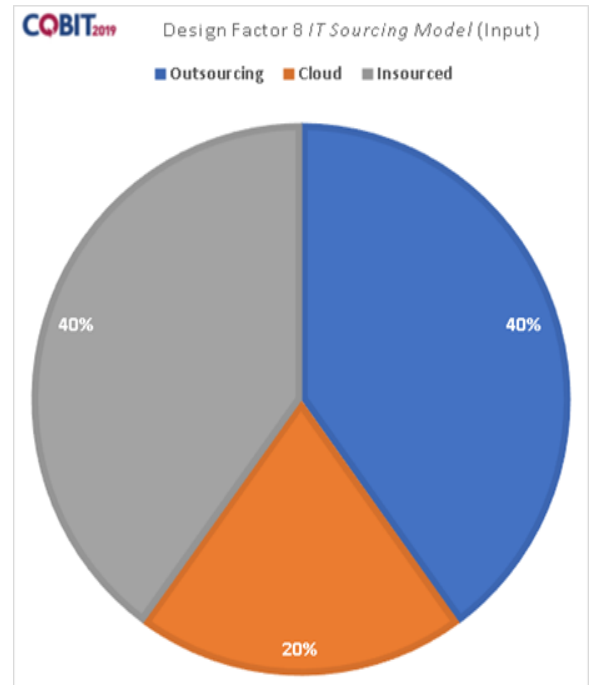

Gambar 9. Desain Factor 8 (IT Sourching Model).

Berdasarkan hasil wawancara pada perusahaan yang sudah dijelaskan pada Gambar 9. Maka dapat dijelaskan bahwa peranan Outsorcing dan Insourching berperan besar dalam penerapan IT di PT.XYZ, yang mana perusahaan menggunakan pihak Outsorcing penyedia layanan bagi operasional pemasaran dan kinerja perusahaan dan Insourching adalah karyawan yang mengoperasikan sistem yang digunakan oleh perusahaan. 


\section{Journal of Computer and Information Systems Ampera}

Vol. 3, No. 1, January 2022 e-ISSN: 2775-2496

https://journal-computing.org/index.php/journal-cisa/index

\subsection{Desain Factor 9: (IT Implementation Method)}

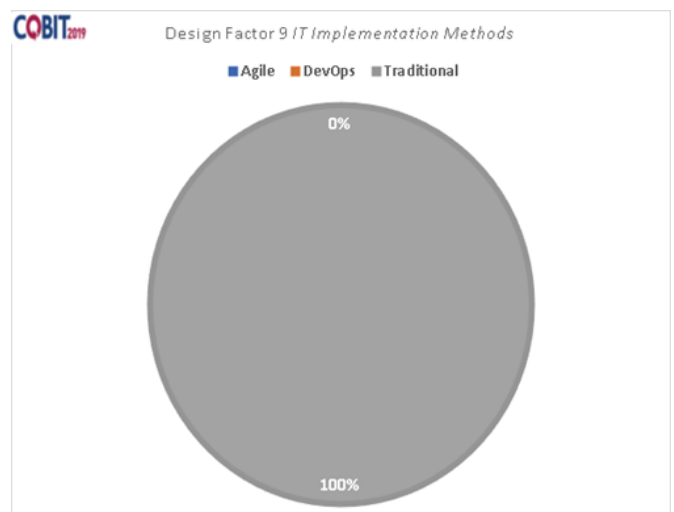

Gambar 10. Desain Factor 9 (IT Implementation Method).

Pada Gambar 10. Terkait dengan IT Implementation Method perusahaan PT.XYZ menggunakan metode Traditional dengan cara menggunakan pendekatan yang lebih klasik terhadap pengembangan perangkat lunak, data ini di dapatkan dari hasil wawancara karyawan bagian operasional terkait IT.

\subsection{Desain Factor 10: (Technology Adaption Strategy)}

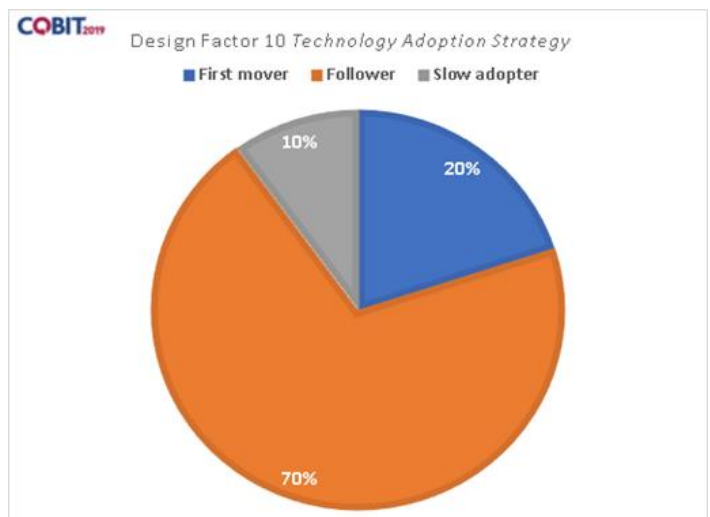

Gambar 11. Desain Factor 10 (Technology Adaption Strategy).

Pada Gambar 11. Menjelaskan Desain Factor 10 terkait Technology Adoption Strategy pada perusahaan PT.XYZ, dimana perusahaan merupakan follower dengan persentase $70 \%$ secara kompleks 
Journal of Computer and Information Systems Ampera

Vol. 3, No. 1, January 2022 e-ISSN: 2775-2496

https://journal-computing.org/index.php/journal-cisa/index

menunjukkan bahwa dalam mengadopsi TI perusahaan tidak berinovasi secara terus menerus hanya mengikuti teknologi yang ada.

\subsection{Desain Factor 11: (All Design Factor)}

Dalam proses tersebut maka dapat dilihat beberapa data yang menunjukkan domain pada diagram sisi positif dan negatif, yang artinya sisi positif merupakan proses prioritas bagi perusahaan PT.XYZ sedangkan sebaliknya sisi negatif menunjukkan bukanlah proses skala prioritas bagi perusahaan, dari beberapa dapat diambil beberapa skala prioritas dengan menghasilkan target kapabilitas level 3 dan 4 yaitu Untuk target kapabilitas level 3 EDM02 (Ensured Benefits Delivery), APO09 (Managed Service Agreements), AP011 (Managed Quality), DSS02 (Managed Services Request \& Incidents), DSS06 (Managed Business Process Controls). Dan untuk target kapabilitas 4 APO08 (Managed Relationship), AP012 (Managed Risk), APO13 (Managed Security), DSS04 (Managed Contiunity), DSS05 (Managed Sequrity Services).

\section{KESIMPULAN}

Setelah dilakukan penelitian dan pengolahan data analisis dan tata kelola yang di dapat dari PT.XYZ, hasil yang didapatkan merupakan beberapa proses penting antara lain ialah AP008 (Managed Relationship), AP012 (Managed Risk), AP013 (Managed Security), DSS04 (Managed Contiunity), DSS05 (Managed Sequrity Services). Proses tersebut dinilai penting sebab memiliki skala prioritas dengan target tinggi sehingga perlu untuk selalu diutamakan demi mencapai tujuan perusahaan yang lebih baik lagi menggunakan sarana teknologi informasi.

\section{REFERENSI}

[1] S. F. Bayastura, S. Krisdina, and A. P. Widodo, "Analisis Dan Perancangan Tata Kelola Teknologi Informasi Menggunakan Framework Cobit 2019 Pada Pt . Xyz Analysis and Design of Information Technology Governance Using the Cobit 2019 At Pt. Xyz," vol. 4, no. 1, pp. 68-75, 2021, doi: 10.33387/jiko.

[2] G. I. Belo, Y. T. Wiranti, and L. H. Atrinawati, "Perancangan Tata Kelola Teknologi Informasi Menggunakan Cobit 2019 Pada PT 


\section{Journal of Computer and Information Systems Ampera}

Vol. 3, No. 1, January 2022 e-ISSN: 2775-2496

https://journal-computing.org/index.php/journal-cisa/index

Telekomunikasi Indonesia Regional VI Kalimantan," JUSIKOM PRIMA (Jurnal Sist. Inf. Ilmu Komput. Prima), vol. 4, no. 1, pp. 23-30, 2020.

[3] A. M. Fikri, H. S. Priastika, N. Octaraisya, S. Sadriansyah, and L. H. Trinawati, "Rancangan Tata Kelola Teknologi Informasi Menggunakan Framework COBIT 2019 (Studi Kasus: PT XYZ)," Inf. Manag. Educ. Prof. J. Inf. Manag., vol. 5, no. 1, p. 1, 2020, doi: 10.51211/imbi.v5i1.1410.

[4] J. A. I. Belegur, C. Rudianto, and M. Sitokdana, "Evaluasi Tata Kelola Teknologi Informasi Dinas Pariwisata dan Kebudayaan Kota Ambon Menggunakan Framework Cobit 5.0 pada Domain Monitor, Evaluate And Asses (MEA)," Aiti, vol. 15, no. 2, pp. 107-114, 2018, doi: 10.24246/aiti.v15i2.107-114.

[5] P. N. Anastasia and L. H. Atrinawati, "Perancangan Tata Kelola Teknologi Informasi Menggunakan Framework Cobit 2019 Pada Hotel Xyz," JSI J. Sist. Inf., vol. 12, no. 2, pp. 1-9, 2020, doi: 10.36706/jsi.v12i2.12329.

[6] P. N. Anastasia, L. H. Atrinawati, P. Studi, S. Informasi, and I. T. Kalimantan, "Perancangan Tata Kelola Teknologi Informasi Menggunakan Framework Cobit 2019 Pada Hotel XYZ” vol. 12, no. 2, 2020. 